\title{
Vitamin D - Beyond Bones: Its Relationship to Obesity, Metabolic Syndrome, and Diabetes
}

\author{
Shannon Wongvibulsin*, Sondra Vazirani, Zhaoping Li and David Heber
}

UCLA Center for Human Nutrition, 900 Veteran Avenue, Warren Hall, Los Angeles, CA 90095, USA

\begin{abstract}
While vitamin D has long been known as an essential nutrient for the prevention of bone disorders, vitamin D deficiency has recently been linked to a number of chronic disease states. This review analyzes the epidemiological, clinical, and mechanistic data concerning the relationship between vitamin D status and obesity, metabolic syndrome (MetS), and diabetes. The increased understanding of the role of vitamin D has promoted researchers to study vitamin D as a potential target for the prevention and treatment of multiple chronic diseases.
\end{abstract}

Keywords: Vitamin D, obesity, metabolic syndrome (MetS), diabetes.

\section{INTRODUCTION}

Vitamin D historically has been viewed solely as an essential nutrient for the prevention of bone disorders, such as rickets and osteomalacia [1]. However, it is now postulated that low vitamin $D$ status is linked to other common chronic diseases such as hypertension [2], cardiovascular diseases [3], diabetes mellitus [4], and several types of cancer [5]. In a large cohort study, serum calcidiol (25-hydroxyvitamin D, 25(OH)D) concentrations were inversely associated with all-cause and cause-specific mortality. In particular, vitamin D deficiency $(25(\mathrm{OH}) \mathrm{D}$ concentration $<30 \mathrm{nmol} / \mathrm{L})$ was strongly associated with mortality from cardiovascular and respiratory diseases, cancer, and all-cause mortality [6].

Vitamin D's theoretical link to widespread metabolic processes is consistent with the discovery of the mitochondrial enzyme 25-hydroxyvitamin $D_{3}-1 \alpha-$ hydroxylase (1a-hydroxylase) in a broad expanse of cells and tissues [7]. Breast, prostate, lung, skin, lymph nodes, colon, pancreas, adrenal medulla, and brain cells (cerebellum and cerebral cortex) contain the $1 \alpha-$ hydroxylase [7] and can synthesize calcitriol $(1,25-$ dihydroxyvitamin D, 1,25(OH)2D) [8]. In addition, calcitriol, the active form of vitamin $\mathrm{D}$, modulates cell proliferation and differentiation [8].

Furthermore, the obesity epidemic closely parallels that of vitamin $D$ deficiency and recent research suggests that the two conditions may be related [9]. Some studies even propose that deficiency in this vitamin is a potential cause of obesity [10]. As will be described, it is plausible that vitamin D deficiency can

*Address correspondence to this author at the UCLA Center for Human Nutrition, 900 Veteran Avenue, Warren Hall, Los Angeles, CA 90095, USA; Tel: (310) 825-8173; Fax: (310) 794-8837; E-mail: swongvi1@jhmi.edu have numerous detrimental effects on health including obesity, metabolic syndrome, and type 2 diabetes.

\section{VITAMIN D DEFICIENCY}

Many factors contribute to vitamin $D$ deficiency: inadequate exposure to sunlight, lack of vitamin $D$ containing foods in the diet, aging, fat malabsorption syndromes, and increased catabolism of calcitriol and calcidiol [11].

Although the skin can naturally synthesize vitamin $D$ when exposed to the sun's ultraviolet $B$ (UVB) rays, the use of sunscreens can block these rays and decrease the conversion from the precursor into its active form. In fact, a sun protection factor (SPF) of 30 reduces the synthesis of vitamin $D$ in the skin by more than $95 \%$ [12]. Nevertheless, the use of sunscreen is increasing in prevalence due to rising concerns surrounding UV exposure and the development of skin cancers. Since melanin acts as an effective sunscreen, those with darker skin exposed to the same amount of ultraviolet radiation will produce less vitamin $D$ than those with lighter skin [13-14]. This supports the finding that there is a higher prevalence of hypovitaminosis $D$ in women of the African American race compared to their white counterparts [14].

Even with a well-balanced diet, it can be difficult to obtain sufficient levels of vitamin $D$ solely via food intake since few foods naturally contain or are fortified with vitamin D. Moreover, food that is fortified is often not adequate enough to counteract vitamin $D$ deficiency [11]. A recent dietary survey indicates that vitamin $D$ intake below recommended levels are common; more than $75 \%$ of the population in Germany, the United States, and the United Kingdom do not meet the recommended intakes of vitamin D [15]. 
Because the cutaneous synthesis of vitamin $D_{3}$ declines with increased age, aging is also a risk factor for vitamin $D$ deficiency if dietary intake or sun exposure does not compensate for decreased synthesis [16]. The Korea National Health and Nutrition Examination Survey (KNHANES IV) linked low vitamin $D$ levels to sarcopenia, the loss of skeletal muscle mass, quality, and strength. This finding supports the correlation between vitamin $\mathrm{D}$ deficiency and increased risk of falls in the elderly. Thus, addressing hypovitaminosis $\mathrm{D}$ may confer even more benefits than previously understood and prolong the physical capabilities in the elderly through protective effects against osteomuscular-degeneration [17].

Since modification of the gastrointestinal tract influences nutrient absorption, vitamin $D$ deficiency after bariatric surgery is common [18]. With bariatric surgery, and in particular, gastric bypass, nutrients from the diet and general multivitamins do not reliably prevent nutritional deficiencies. Thus, supplementation is often required [19]. However, bariatric patients oftentimes cannot absorb fat-soluble vitamins and can become deficient in vitamin $D[20]$.

Furthermore, vitamin $D$ levels can decrease due to conditions that enhance vitamin $\mathrm{D}$ excretion or catabolism. In individuals suffering from nephrotic syndrome, calcidiol binds with vitamin $\mathrm{D}$ binding protein and is then lost through the urine [20-21]. Certain medical conditions and drugs can also enhance the catabolism of calcitriol and calcidiol. For instance, medications used to treat HIVIAIDS can contribute to vitamin D catabolism [22-23]. Furthermore, individuals who suffer from disorders, such as primary hyperparathyroidism, chronic granuloma-forming disorders, and some lymphomas, characterized by the increased catabolism of calcifidiol and calcitriol, are at higher risk of hypovitaminosis D [20,24-25].

In summary, there are many prevalent forces that promote vitamin $\mathrm{D}$ deficiency. Lack of or blockade of UV rays, dietary insufficiency/malabsorption, or catabolism of vitamin D can all contribute to low levels; the plausible relationship of low levels of vitamin $D$ to chronic disorders will be described in this paper.

\section{VITAMIN D AND OBESITY}

A growing body of epidemiological evidence has emerged linking vitamin $D$ with obesity. An inverse relationship has been reported between adiposity and circulating $25(\mathrm{OH}) \mathrm{D}$ concentrations, the physiologically relevant marker of vitamin $D$ status [26-30]. Additionally, low circulating concentrations of $25(\mathrm{OH}) \mathrm{D}$ were independently associated with increased $\mathrm{BMI}$ and fat mass [31-34]. Kamycheva et al. reported that the lowest quartile of vitamin $D$ intake ( $<2.8 \mu \mathrm{g} / \mathrm{day})$ was an independent predictor of obesity in both men and women [28]. Similarly, Parikh et al. concluded that serum $25(\mathrm{OH}) \mathrm{D}$ levels were negatively correlated with BMI and body fat mass [33]. In children, low levels of vitamin $D$ have been found to correlate with higher fat levels and BMls than kids with adequate levels of vitamin D [35]. Rajakumar et al. determined that plasma 25(OH)D was inversely associated with BMI, percentage of total body fat, visceral adipose tissue, and subcutaneous adipose tissue [35]. Conversely, higher vitamin $D$ intake and higher serum levels of $25(\mathrm{OH}) \mathrm{D}$ have been related to lower adiposity [36]. Caron-Jobin et al. analyzed omental and subcutaneous adipose tissue samples from women undergoing gynecological surgeries and determined that serum 25(OH)D was inversely associated with subcutaneous, visceral, and total adipose tissue area, BMI, and total body fat mass [36].

Although a recent review on calcium and/or vitamin D supplementation showed equivocal results as it related to fat loss [37], other authors have provided evidence that supplementation can increase fat oxidation and promote energy loss through increased fecal fat excretion [38]. Further support for the role of vitamin $D$ in body fat reduction was demonstrated from a 12-week, double-blind, randomized, placebocontrolled trial. The vitamin $\mathrm{D}$ group had a statistically significant increase in serum levels of $25(\mathrm{OH}) \mathrm{D}$ which was correlated with a decrease in body fat mass [39].

There are several theories as to how vitamin $\mathrm{D}$ affects weight loss and obesity. The first theory involves calcium's ability to boost metabolic rates [40]. Because vitamin $D$ is essential for the absorption of calcium in the intestines, vitamin $D$ deficiency can result in decreased calcium absorption. Since calcium can increase thermogenesis and thereby boost the body's metabolism, diminishing the amount of intracellular calcium can result in lower metabolic rates. It has been shown in both mice and humans that the higher the levels of calcium there are in a fat cell, the more fat the cell will burn, corresponding to a protective effect against weight gain. Furthermore, there is accumulating evidence from animal and human studies that suggests that dietary calcium may be beneficial for weight management [40]. Alterations in calcium metabolism have been noted in obese patients. For 
instance, a 12 week RCT consisting of 53 overweight or obese subjects with very low calcium intake $(<600$ $\mathrm{mg} /$ day) demonstrated that an energy-restricted diet supplemented with calcium and vitamin $D_{3}$ resulted in a significantly greater reduction in fat mass compared with those solely on calorie restriction [41]. This reaffirms previous findings that combined supplementation with calcium and vitamin $D$ can aid in body and visceral fat loss [41-43].

Another theory is that obese patients have decreased bioavailability of vitamin $D$ due to sequestration of vitamin $D$ in body fat compartments. Studies with UVB radiation suggest that obesity does not significantly impact the skin's production of vitamin $D_{3}$, supporting the bioavailability hypothesis [34].

A third proposed mechanism relates to the effects of vitamin $D$ on appetite and energy consumption. Deficiency in vitamin $D$ can result in the stimulation of the Agouti Related Protein/Neuropeptide $Y$ (AgRP/NPY) and suppression of the proOpiomelanocortin/Cocaine-Amphetamin-Regulated

Transcription (POMC/CART) pathway. These alterations lead to an increase in appetite and decrease in energy consumption, contributing to obesity $[39,44]$. Zemel studied 2 groups of transgenic mice on identical caloric diets. Those that expressed the agoutigene responded to low calcium diets with accelerated weight gain and fat accretion, whereas high calcium diets markedly inhibited lipogenesis, accelerated lipolysis, increased thermogenesis and suppressed fat accretion and weight gain [45]. Because the POMC/CART pathway normally functions to suppress feeding and increase energy expenditure when activated, suppression of this pathway can result in overeating and a disruption of energy homeostasis [46].

Another theory linking vitamin $D$ to obesity involves the teleological phenomena. Foss et al. proposed that vitamin $D$ originated as a photoreceptor system in primitive organisms and retained this role as UVB radiation-sensitive sensor. Following this theory, a decrease in UV radiation exposure could signal a winter response, which confers endurance to the cold winter environment. The adaptive response would then result in an increase in body size through the accumulation of fat mass (obesity) and winter metabolism (metabolic syndrome) to increase thermogenic capacity. In today's world of abundance, these anomalous adaptations, signaled by the fall of vitamin $D$ levels, could be contributors to the development of common obesity [10].
Vimaleswaran et al. suggested that obesity is a causal factor in the development of vitamin $D$ deficiency, rather than vitamin $D$ deficiency being a causal factor in the development of obesity. However, the authors suggest that vitamin $D$ supplementation could provide health benefits regardless of the directionality. If obesity causes vitamin $\mathrm{D}$ deficiency, monitoring and treating vitamin $\mathrm{D}$ deficiency might potentially reduce some of the adverse health effects of obesity. Conversely, if low vitamin D levels cause obesity, encouraging people to take vitamin D supplements might help with obesity treatment and management [47].

\section{VITAMIN D AND METABOLIC SYNDROME}

Metabolic syndrome (MetS) is a disorder of energy storage associated with central obesity, hypertension, hyperglycemia, and dyslipidemia. Serum levels of calcidiol have been known to be inversely correlated with the prevalence of MetS [48-49]. A recent study found that serum calcidiol concentrations $\leq 23 \mathrm{ng} / \mathrm{mL}$ were correlated with up to a $74 \%$ increased risk of MetS in comparison to subjects with concentrations of $\geq 34 \mathrm{ng} / \mathrm{mL}$ [50]. Furthermore, a cross-sectional survey found similar results. Most notably, the findings were independent of the degree of obesity [51]. Additionally, data from 4,727 black and white young men and women from the Coronary Artery Risk Development in Young Adults study showed that dietary and supplemental vitamin $D$ intake was inversely related to the development of incident MetS over 20 years of follow-up [52]. Using the National Health and Nutrition Examination Surveys (NHANES) 2003-2006, Maki et al. evaluated the association of vitamin $D$ intake and vitamin $\mathrm{D}$ status with the prevalence of MetS. From this analysis, Maki et al. concluded that higher $25(\mathrm{OH}) \mathrm{D}$ levels and greater dietary vitamin $\mathrm{D}$ intake are associated with reduced prevalence of MetS [53].

Numerous studies have found low serum levels of vitamin $\mathrm{D}$ to be correlated with high triglyceride levels [54-56]. Using data from the Third NHANES $(7,186$ males and 7,902 females 20 years and over), it was determined that the prevalence of high serum triglyceride levels was significantly higher for participants within the first quartile for calcifidiol levels $(<21 \mathrm{ng} / \mathrm{mL})$ than in the fourth quartile $(\geq 37 \mathrm{ng} / \mathrm{mL})(P$ $<0.001$ ) [54]. Additionally, analysis of the 2001-2004 NHANES data (including 3,577 participants between 12-19 years old) demonstrated that individuals in the lowest quartile for calcifidiol levels $(<15 \mathrm{ng} / \mathrm{mL})$ had an increased risk for hypertriglyceridemia than participants 
in the highest quartile (>26 ng/mL) [55]. Furthermore, a cross-sectional study of 149 Spanish school children (ages 8 to 13) demonstrated that children with low serum levels of vitamin $D(<17.4 \mathrm{ng} / \mathrm{mL})$ had higher triglyceride levels than those with higher levels of vitamin $\mathrm{D}(\geq 27.6 \mathrm{ng} / \mathrm{mL})[56]$.

Although epidemiologic and observational studies have suggested that vitamin $D$ deficiency is associated with suboptimal lipid profile, there is still lack of clinical evidence supporting the benefit of vitamin $D$ supplementation on improving lipid profiles [57]. Furthermore, a randomized, placebo-controlled trial demonstrated that the correction of vitamin $D$ deficiency in the short-term does not correct dyslipidemia [58].

Nevertheless, there are several potential mechanisms for the role of vitamin $D$ in lipid metabolism. Lack of vitamin $D$ decreases the ability of the intestines to absorb calcium, which has the ability to lower serum triglyceride levels through the reduction of hepatic triglyceride formation and secretion. Thus, low serum levels of vitamin $D$ can result in low calcium levels and increased serum triglycerides [56,59]. Additionally, vitamin D suppresses serum concentrations of parathyroid hormone (PTH). When vitamin D levels are low, elevated PTH concentrations lead to a reduction in plasma post-heparin lipolytic activity. Consequently, low serum vitamin $D$ levels can result in decreased peripheral removal of triglycerides and contribute to higher triglyceride levels $[56,60]$. Furthermore, vitamin $D$ can induce the expression of very low density lipoprotein (LDL)-cholesterol receptors on cells like macrophages [61]. As a result, when serum levels of vitamin $D$ are low, the induction of these receptors does not occur and the removal of LDL from circulation is impaired.

Studies of vitamin D and MetS suggest that supplementation may help insulin resistance and impaired glucose tolerance. In a small RCT of 84 women of South Asian origin living in New Zealand, the participants were randomized into either vitamin $D$ supplementation (4000 IU $25(\mathrm{OH}) \mathrm{D}_{3}$ per day) or placebo for 6 months. Baseline measurements indicated that all of the participants were vitamin $\mathrm{D}$ deficient (serum $25(\mathrm{OH}) \mathrm{D}_{3}<50 \mathrm{nmol} / \mathrm{L}$ ) and insulin resistant [62]. Significant improvements in insulin sensitivity and insulin resistance as well as a decrease in fasting insulin levels were measured in the supplementation group [63]. However, in a metaanalysis including 15 RCTs, George et al. concluded that there is insufficient evidence of beneficial effect to recommend vitamin $D$ supplementation in non-deficient patients as a means of improving glucose control or insulin resistance in patients with diabetes or impaired glucose tolerance [64]. More recent research suggests that it may be beneficial to incorporate vitamin $D$ supplementation as part of the treatment of obesity and insulin resistance in adolescences. A RCT with 35 obese adolescences demonstrated that after 6 months, supplementation with vitamin D (4000 IU/day) resulted in a statistically significant decrease in fasting insulin levels and insulin resistance compared with the placebo control group [65].

\section{VITAMIN D AND DIABETES}

Because the association of diabetes with latitude and sun exposure, vitamin $D$ deficiency has been examined as a potential culprit in the development of diabetes mellitus [66]. A cross-sectional survey of a New Zealand Polynesian and Caucasian workforce found that individuals recently diagnosed with diabetes mellitus and impaired glucose tolerance had significantly lower serum concentrations of $25(\mathrm{OH}) \mathrm{D}$ compared with controls matched for sex, age, and ethnicity [67]. Additionally, analysis of the serum concentrations of $25(\mathrm{OH}) \mathrm{D}$ of 6,228 people surveyed as part of NHANES (1988-1994) displayed an inverse association between vitamin $D$ status and diabetes in non-Hispanic whites and Mexican Americans [68]. The 2001-2006 NHANES with 5,806 participants noted that abdominal obesity and insufficient levels of $25(\mathrm{OH}) \mathrm{D}$ interact to increase the risk of insulin resistance. Vitamin D insufficiency and obesity are both individual risk factors for insulin resistance. However, when abdominal obesity and insufficient vitamin $D$ levels occur in the same person, the forces promoting insulin resistance are synergistic [69]. In a cohort study, Mattila et al. noted a significant inverse association between serum concentrations of $25(\mathrm{OH}) \mathrm{D}$ and the risk for type 2 diabetes. Although the study was longitudinal, a major limitation of the study was that blood samples were not collected at the same time of year for all the subjects. Since sun exposure impacts serum vitamin $D$ levels, the discrepancy between the seasons in which blood sample were collected could have impacted the results [70].

When vitamin $\mathrm{D}$ supplementation was prescribed to treat vitamin $\mathrm{D}$ deficiency, glucose tolerance was found to improve [71]. In a meta-analysis of observational studies, Mitri et al. found that vitamin D intake greater than $500 \mathrm{IU} /$ day decreased the risk of type 2 diabetes 
by $13 \%$ compared with vitamin $D$ intake less than $200 \mathrm{IU} /$ day [4]. Furthermore, the authors reported that individuals with the highest vitamin D status $(>25 \mathrm{ng} / \mathrm{ml})$ had a $43 \%$ lower risk of developing type 2 diabetes when compared with those in the lowest group $(<14 \mathrm{ng} / \mathrm{ml})$. Additionally, with post hoc analysis of 2 trials among patients with baseline glucose intolerance, the authors noted that vitamin $D$ supplementation improved insulin resistance [4]. Yet, vitamin D supplementation to decrease insulin resistance and improve glycemic control in vitamin D deficient type 2 diabetic patients have not revealed conclusive results [72].

Several mechanisms for the role of vitamin $D$ and diabetes have been postulated. Vitamin $D$ has been shown to play a regulatory role in the pancreas, especially in the beta cells. Animal models have demonstrated that vitamin $D$ deficiency inhibits pancreatic insulin secretion [66,73]. Moreover, beta cells contain the receptors for calcitriol and the effector portion of the vitamin D pathway, vitamin D-dependent calcium-binding protein (calbindin- $D_{28 \mathrm{k}}$ ) which is known to confer protective effects against cytokine-mediated beta cell death $[66,74]$. Vitamin $D_{3}$ can also prevent interleukin-1 beta (IL-1 $\beta$ ) and interferon gamma (IFN- $\gamma$ ) inhibition of insulin synthesis and secretion in beta cells [75].

Studies have suggested that $25(\mathrm{OH}) \mathrm{D}$
concentrations are positively associated with
adiponectin, a protein hormone involved in glucose regulation. While most of these studies are small, Vaidya et al. analyzed data from 2 large populations $(1,206$ women from the Nurses' Health Study I and 439 men from the Health Professionals Follow-Up Study) and noted an independent association between 25(OH)D and adiponectin using multivariable linear regression [76]. Additionally, lower adiponectin levels correlate with insulin resistance and MetS [77].

Lastly, vitamin D deficiency can result in hyperparathyroidism, which leads to insulin resistance and diabetes through its impact on glucose metabolism [68,78-79]. In fact, parathyroidectomy has been shown to result in the regression of diabetes and impaired glucose tolerance in some patients [80].

\section{VITAMIN D AND INFLAMMATION}

Another link between vitamin D and obesity, diabetes, and MetS may be due to its role in inflammation. Research has demonstrated that vitamin
D supplementation can reduce inflammation. In a 1year randomized intervention, overweight and obese subjects took 40,000 IU vitamin D (cholecalciferol) per week, 20,000 IU vitamin D per week, or a placebo. At baseline and after the 1-year intervention, serum levels of pro-inflammatory cytokines, interleukin 6 (IL-6), tumor necrosis factor-alpha (TNF- $\alpha$ ), and high sensitive $\mathrm{C}$-reactive protein (hs-CRP), were measured. Beilfuss et al. found significant associations between IL-6, TNF$\alpha$, vitamin $D$ and insulin resistance indices at baseline [81]. The authors noted a positive association between levels of TNF- $\alpha$ and insulin resistance, but a negative association between serum 25(OH)D and insulin resistance. After the 1-year intervention with vitamin $D$, they found a decrease in serum IL-6 levels [81]; IL-6 inhibits adiponectin gene expression which promotes anti-atherogenic and anti-inflammatory activities [77].

Nevertheless, the relationship between vitamin $D$ and certain pro-inflammatory biomarkers is not clear. For instance, in the previously mentioned study, hsCRP levels were significantly increased, yet neither insulin resistance nor TNF- $\alpha$ were influenced by a 1year vitamin $D$ supplementation [81]. It is possible that the lack of association between TNF- $\alpha$ and $25(\mathrm{OH}) \mathrm{D}$ was due to the fact that the majority of their study population had sufficient levels of vitamin $D$ at baseline and that vitamin $\mathrm{D}$ supplementation could have had a more profound effect in vitamin $D$ deficient subjects. Other authors noted a significant negative association between TNF- $\alpha$ and $25(\mathrm{OH}) \mathrm{D}$ in 69 healthy women even after accounting for body fat mass, menopausal age, and other confounding factors [82]. Additionally, a number of studies have demonstrated the significant favorable impact of vitamin $D$ supplementation on proinflammatory cytokines such as TNF- $\alpha, \mathrm{IL}-6$, and IL-10 in select groups (type 2 diabetic patients [83], infants with congestive heart failure [84], patients on hemodialysis with end stage kidney disease [85], and patients with colorectal neoplasm [86]).

\section{DISCUSSION}

There are significant challenges when trying to interpret the vitamin $D$ literature. While vitamin $D$ deficiency has been linked to numerous conditions, the majority of these findings are based on cross-sectional studies and thus, directionality cannot be established (i.e. it remains unclear whether inadequate levels of vitamin $D$ cause the disorder or if the low level of vitamin $D$ is a consequence of the disorder). Secondly, many vitamin $D$ studies have small sample sizes and mixed results, causing meta-analyses to report 
"negative" findings. Thirdly, many studies have different doses and duration of supplementation, making direct comparisons difficult.

Because vitamin $D$ deficiency is becoming an increasing problem, clinicians are working to improve early diagnosis and treatment of hypovitaminosis $D$ and help patients take advantage of the health benefits of maintaining adequate serum levels of vitamin $D$. While vitamin $D$ can be synthesized naturally in the skin of healthy individuals and obtained from supplementation and in the diet through natural and fortified sources, this compound is emerging as a promising therapeutic. Nevertheless, the mechanisms underlying the role of vitamin $\mathrm{D}$ in disease states are still not well understood and further research is required to examine the potential of vitamin $D$ supplementation as a possible therapeutic or preventative measure. Furthermore, there is concern that over-supplementation can activate calcium-mediated apoptotic pathway in human adipose tissue [87]. Overall, the parallel between the rise of vitamin $\mathrm{D}$ deficiency and the prevalence of obesity, MetS, and diabetes as well as cardiovascular and other diseases have suggested that future researchers target vitamin $D$ as a potential therapeutic for prevention and treatment of chronic diseases [88].

\section{REFERENCES}

[1] Heaney RP. Long-latency deficiency disease: insights from calcium and vitamin D. Am J Clin Nutr 2003; 78(5): 912-9.

[2] Witham MD, Nadir MA, Struthers AD. Effect of vitamin D on blood pressure: a systematic review and meta-analysis. J Hypertens 2009; 27(10): 1948-54. http://dx.doi.org/10.1097/HJH.0b013e32832f075b

[3] Grandi NC, Breitling LP, Brenner H. Vitamin D and cardiovascular disease: systematic review and meta-analysis of prospective studies. Prev Med 2010; 51(3-4): 228-33. http://dx.doi.org/10.1016/j.ypmed.2010.06.013

[4] Mitri J, Muraru MD, Pittas AG. Vitamin D and type 2 diabetes: a systematic review. Eur J Clin Nutr 2011; 65(9): 1005-15. http://dx.doi.org/10.1038/ejcn.2011.118

[5] Grant WB. How strong is the evidence that solar ultraviolet B and vitamin $D$ reduce the risk of cancer? An examination using Hill's criteria for causality. Dermatoendocrinol 2009; 1(1): $17-24$

http://dx.doi.org/10.4161/derm.1.1.7388

[6] Schottker B, Haug U, Schomburg L, et al. Strong associations of 25-hydroxyvitamin D concentrations with allcause, cardiovascular, cancer, and respiratory disease mortality in a large cohort study. Am J Clin Nutr 2013; 97(4): 782-93. http://dx.doi.org/10.3945/ajcn.112.047712

[7] Vasquez A, Manso G, Cannell J. The clinical importance of vitamin $D$ (cholecalciferol): a paradigm shift with implications for all healthcare providers. Altern Ther Health Med 2004; 10(5): 28-36.

[8] Zehnder D, Bland R, Williams $M C$, et al. Extrarenal expression of 25-hydroxyvitamin d(3)-1 alpha-hydroxylase. J Clin Endocrinol Metab 2001; 86(2): 888-94.
[9] Vanlint S. Vitamin D and Obesity. Nutrients 2013; 5: 949-56. http://dx.doi.org/10.3390/nu5030949

[10] Foss YJ. Vitamin D deficiency is the cause of common obesity. Med Hypotheses 2009; 72(3): 314-21. http://dx.doi.org/10.1016/j.mehy.2008.10.005

[11] Holick MF, Chen TC. Vitamin D deficiency: a worldwide problem with health consequences. Am J Clin Nutr 2008; 87(4): 1080S-6S.

[12] Matsuoka LY, Ide L, Wortsman J, MacLaughlin JA, Holick MF. Sunscreens suppress cutaneous vitamin D3 synthesis. J Clin Endocrinol Metab 1987; 64(6): 1165-8. http://dx.doi.org/10.1210/jcem-64-6-1165

[13] Schwartz GG, Blot WJ. Vitamin D status and cancer incidence and mortality: something new under the sun. J Natl Cancer Inst 2006; 98(7): 428-30. http://dx.doi.org/10.1093/jnci/djij27

[14] Nesby-O'Dell S, Scanlon KS, Cogswell ME, et al. Hypovitaminosis D prevalence and determinants among African American and white women of reproductive age: third National Health and Nutrition Examination Survey, 19881994. Am J Clin Nutr 2002; 76(1): 187-92.

[15] Troesch B, Hoeft B, McBurney M, Eggersdorfer M, Weber P. Dietary surveys indicate vitamin intakes below recommendations are common in representative Western countries. Br J Nutr 2012; 108(4): 692-8. http://dx.doi.org/10.1017/S0007114512001808

[16] MacLaughlin J, Holick MF. Aging decreases the capacity of human skin to produce vitamin D3. J Clin Invest 1985; 76(4): 1536-8.

http://dx.doi.org/10.1172/JCl112134

[17] Kim MK, Baek KH, Song $\mathrm{KH}$, et al. Vitamin D deficiency is associated with sarcopenia in older Koreans, regardless of obesity: the Fourth Korea National Health and Nutrition Examination Surveys (KNHANES IV) 2009. J Clin Endocrinol Metab 2011; 96(10): 3250-6. http://dx.doi.org/10.1210/jc.2011-1602

[18] Shankar P, Boylan M, Sriram K. Micronutrient deficiencies after bariatric surgery. Nutrition 2010; 26(11-12): 1031-7. http://dx.doi.org/10.1016/j.nut.2009.12.003

[19] Saltzman E, Karl JP. Nutrient Deficiencies After Gastric Bypass Surgery. Annu Rev Nutr 2013. http://dx.doi.org/10.1146/annurev-nutr-071812-161225

[20] Holick MF, Binkley NC, Bischoff-Ferrari HA, Gordon CM, Hanley DA, Heaney RP, et al. Evaluation, treatment, and prevention of vitamin D deficiency: an Endocrine Society clinical practice guideline. J Clin Endocrinol Metab 2011; 96(7): 1911-30

http://dx.doi.org/10.1210/jc.2011-0385

[21] Holick MF. Vitamin D deficiency. N Engl J Med 2007; 357(3): 266-81. http://dx.doi.org/10.1056/NEJMra070553

[22] Viard JP, Souberbielle JC, Kirk O, et al. Vitamin D and clinical disease progression in HIV infection: results from the EuroSIDA study. AIDS 2011; 25(10): 1305-15. http://dx.doi.org/10.1097/QAD.0b013e328347f6f7

[23] Maria T, Thomas S, Marc VG, Stephane DW. Factors associated with vitamin D deficiency in a population of 2044 HIV-infected patients. Clin Nutr 2013.

[24] Adams JSHM. Hypercalcemia caused by granuloma-forming disorders. In: Favus MJ, editor. Primer on the metabolic bone diseases and disorders of mineral metabolism. 6th ed. Washington (DC): American Society for Bone and Mineral Research; 2006; pp. 200-2.

[25] Grey A, Lucas J, Horne A, Gamble G, Davidson JS, Reid IR. Vitamin $D$ repletion in patients with primary hyperparathyroidism and coexistent vitamin $D$ insufficiency. $J$ Clin Endocrinol Metab 2005; 90(4): 2122-6. http://dx.doi.org/10.1210/jc.2004-1772 
[26] Parikh SJ, Edelman M, Uwaifo GI, et al. The relationship between obesity and serum 1,25-dihydroxy vitamin D concentrations in healthy adults. J Clin Endocrinol Metab 2004; 89(3): 1196-9.

http://dx.doi.org/10.1210/jc.2003-031398

[27] Arunabh S, Pollack S, Yeh J, Aloia JF. Body fat content and 25-hydroxyvitamin $D$ levels in healthy women. J Clin Endocrinol Metab 2003; 88(1): 157-61. http://dx.doi.org/10.1210/jc.2002-020978

[28] Kamycheva E, Joakimsen RM, Jorde R. Intakes of calcium and vitamin $\mathrm{D}$ predict body mass index in the population of Northern Norway. J Nutr 2003; 133(1): 102-6.

[29] Bell NH, Epstein S, Greene A, Shary J, Oexmann MJ, Shaw S. Evidence for alteration of the vitamin D-endocrine system in obese subjects. J Clin Invest 1985; 76(1): 370-3. http://dx.doi.org/10.1172/JCl111971

[30] Compston JE, Vedi S, Ledger JE, Webb A, Gazet JC, Pilkington TR. Vitamin D status and bone histomorphometry in gross obesity. Am J Clin Nutr 1981; 34(11): 2359-63.

[31] Zemel MB, Richards J, Mathis S, Milstead A, Gebhardt L, Silva E. Dairy augmentation of total and central fat loss in obese subjects. Int J Obes (Lond) 2005; 29(4): 391-7. http://dx.doi.org/10.1038/sj.ijo.0802880

[32] Zemel MB, Thompson W, Milstead A, Morris K, Campbell P. Calcium and dairy acceleration of weight and fat loss during energy restriction in obese adults. Obes Res 2004; 12(4): 582-90.

http://dx.doi.org/10.1038/oby.2004.67

[33] Parikh SJ, Edelman M, Uwaifo GI, Freedman RJ, SemegaJanneh M, Reynolds $J$, et al. The relationship between obesity and serum 1,25-dihydroxy vitamin D concentrations in healthy adults. J Clin Endocrinol Metab 2004; 89(3): 11969.

http://dx.doi.org/10.1210/jc.2003-031398

[34] Wortsman J, Matsuoka LY, Chen TC, Lu Z, Holick MF. Decreased bioavailability of vitamin $D$ in obesity. Am J Clin Nutr 2000; 72(3): 690-3.

[35] Rajakumar K, de las HJ, Chen TC, Lee S, Holick MF, Arslanian SA. Vitamin D status, adiposity, and lipids in black American and Caucasian children. J Clin Endocrinol Metab 2011; 96(5): 1560-7.

http://dx.doi.org/10.1210/jc.2010-2388

[36] Caron-Jobin M, Morisset AS, Tremblay A, Huot C, Legare D, Tchernof A. Elevated serum $25(\mathrm{OH}) \mathrm{D}$ concentrations, vitamin $\mathrm{D}$, and calcium intakes are associated with reduced adipocyte size in women. Obesity (Silver Spring) 2011; 19(7): 1335-41.

http://dx.doi.org/10.1038/oby.2011.90

[37] Soares MJ, Chan SP-D, Ghanbari MH. Calcium and vitamin D for obesity: a review of randomized controlled trials. Eur J Clin Nutr 2011; 65(9): 994-1004. http://dx.doi.org/10.1038/ejcn.2011.106

[38] Soares MJ, Murhadi LL, Kurpad AV, Chan She Ping-Delfos WL, Piers LS. Mechanistic roles for calcium and vitamin D in the regulation of body weight. Obes Rev 2012; 13(7): 592605.

http://dx.doi.org/10.1111/j.1467-789X.2012.00986.x

[39] Salehpour A, Hosseinpanah F, Shidfar F, et al. A 12-week double-blind randomized clinical trial of vitamin D3 supplementation on body fat mass in healthy overweight and obese women. Nutr J 2012; 11: 78.

http://dx.doi.org/10.1186/1475-2891-11-78

[40] Zemel MB. Regulation of adiposity and obesity risk by dietary calcium: mechanisms and implications. J Am Coll Nutr 2002; 21(2): 146S-51S. http://dx.doi.org/10.1080/07315724.2002.10719212

[41] Zhu W, Cai D, Wang Y, et al. Calcium plus vitamin D3 supplementation facilitated fat loss in overweight and obese college students with very-low calcium consumption: a randomized controlled trial. Nutr J 2013; 12 : 8.

\section{http://dx.doi.org/10.1186/1475-2891-12-8}

[42] Zemel MB, Thompson W, Milstead A, Morris K, Campbell P. Calcium and dairy acceleration of weight and fat loss during energy restriction in obese adults. Obes Res 2004; 12(4): 582-90.c

[43] Zemel MB, Richards J, Mathis S, Milstead A, Gebhardt L, Silva E. Dairy augmentation of total and central fat loss in obese subjects. Int J Obes (Lond) 2005; 29(4): 391-7. http://dx.doi.org/10.1038/sj.ijo.0802880

[44] Schwartz MW, Niswender KD. Adiposity signaling and biological defense against weight gain: absence of protection or central hormone resistance? J Clin Endocrinol Metab 2004; 89(12): 5889-97. http://dx.doi.org/10.1210/jc.2004-0906

[45] Zemel MB. Mechanisms of dairy modulation of adiposity. $J$ Nutr 2003; 133(1): 252S-6S.

[46] Hill JW. Gene Expression and the Control of Food Intake by Hypothalamic POMC/CART Neurons. The Open Neuroendocrinology Journal 2010; 3: 21-7.

[47] Vimaleswaran KS, Berry DJ, Lu C, et al. Causal relationship between obesity and vitamin $\mathrm{D}$ status: bi-directional Mendelian randomization analysis of multiple cohorts. PLoS Med 2013; 10(2): e1001383.

http://dx.doi.org/10.1371/journal.pmed.1001383

[48] Yin X, Sun Q, Zhang X, et al. Serum 25(OH)D is inversely associated with metabolic syndrome risk profile among urban middle-aged Chinese population. Nutr J 2012; 11: 68. http://dx.doi.org/10.1186/1475-2891-11-68

[49] Muldowney S, Lucey AJ, Paschos G, et al. Relationships between vitamin $D$ status and cardio-metabolic risk factors in young European adults. Ann Nutr Metab 2011; 58(2): 85-93. http://dx.doi.org/10.1159/000324600

[50] Gagnon C, Lu ZX, Magliano DJ, et al. Low serum 25hydroxyvitamin $D$ is associated with increased risk of the development of the metabolic syndrome at five years: results from a national, population-based prospective study (The Australian Diabetes, Obesity and Lifestyle Study: AusDiab). J Clin Endocrinol Metab 2012; 97(6): 1953-61. http://dx.doi.org/10.1210/jc.2011-3187

[51] Minambres I, Sanchez-Hernandez J, Sanchez-Quesada JL, Rodriguez J, de LA, Perez $A$. The association of hypovitaminosis $d$ with the metabolic syndrome is independent of the degree of obesity. ISRN Endocrinol 2012; 2012: 691803.

[52] Fung GJ, Steffen LM, Zhou X, et al. Vitamin D intake is inversely related to risk of developing metabolic syndrome in African American and white men and women over $20 \mathrm{y}$ : the Coronary Artery Risk Development in Young Adults study. Am J Clin Nutr 2012; 96(1): 24-9. http://dx.doi.org/10.3945/ajcn.112.036863

[53] Maki KC, Fulgoni VL, III, Keast DR, Rains TM, Park KM, Rubin MR. Vitamin D intake and status are associated with lower prevalence of metabolic syndrome in U.S. adults: National Health and Nutrition Examination Surveys 20032006. Metab Syndr Relat Disord 2012; 10(5): 363-72. http://dx.doi.org/10.1089/met.2012.0020

[54] Martins D, Wolf M, Pan D, et al. Prevalence of cardiovascular risk factors and the serum levels of 25-hydroxyvitamin $D$ in the United States: data from the Third National Health and Nutrition Examination Survey. Arch Intern Med 2007; 167(11): 1159-65.

http://dx.doi.org/10.1001/archinte.167.11.1159

[55] Reis JP, von MD, Miller ER, III, Michos ED, Appel LJ. Vitamin $\mathrm{D}$ status and cardiometabolic risk factors in the United States adolescent population. Pediatrics 2009; 124(3): e371-e379. http://dx.doi.org/10.1542/peds.2009-0213 
[56] Rodriguez-Rodriguez E, Ortega RM, Gonzalez-Rodriguez LG, Lopez-Sobaler AM. Vitamin D deficiency is an independent predictor of elevated triglycerides in Spanish school children. Eur J Nutr 2010; 50(5): 373-8.

http://dx.doi.org/10.1007/s00394-010-0145-4

[57] Ponda MP, Huang X, Odeh MA, Breslow JL, Kaufman HW. Vitamin D may not improve lipid levels: a serial clinical laboratory data study. Circulation 2012; 126(3): 270-7. http://dx.doi.org/10.1161/CIRCULATIONAHA.111.077875

[58] Ponda MP, Dowd K, Finkielstein D, Holt PR, Breslow JL. The short-term effects of vitamin $\mathrm{D}$ repletion on cholesterol: a randomized, placebo-controlled trial. Arterioscler Thromb Vasc Biol 2012; 32(10): 2510-5. http://dx.doi.org/10.1161/ATVBAHA.112.254110

[59] Barger-Lux MJ, Heaney RP, Lanspa SJ, Healy JC, DeLuca HF. An investigation of sources of variation in calcium absorption efficiency. J Clin Endocrinol Metab 1995; 80(2): 406-11.

[60] Lacour B, Basile C, Drueke T, Funck-Brentano JL. Parathyroid function and lipid metabolism in the rat. Miner Electrolyte Metab 1982; 7(3): 157-65.

[61] Kohno M, Takahashi S, Oida K, et al. 1 alpha,25dihydroxyvitamin D3 induces very low density lipoprotein receptor mRNA expression in HL-60 cells in association with monocytic differentiation. Atherosclerosis 1997; 133(1): 45-9. http://dx.doi.org/10.1016/S0021-9150(97)00112-3

[62] von Hurst PR, Stonehouse W, Matthys C, Conlon C, Kruger MC, Coad J. Study protocol-metabolic syndrome, vitamin D and bone status in South Asian women living in Auckland, New Zealand: a randomised, placebo-controlled, doubleblind vitamin D intervention. BMC Public Health 2008; 8: 267. http://dx.doi.org/10.1186/1471-2458-8-267

[63] von Hurst PR, Stonehouse W, Coad J. Vitamin D supplementation reduces insulin resistance in South Asian women living in New Zealand who are insulin resistant and vitamin $\mathrm{D}$ deficient - a randomised, placebo-controlled trial. Br J Nutr 2010; 103(4): 549-55.

http://dx.doi.org/10.1017/S0007114509992017

[64] George PS, Pearson ER, Witham MD. Effect of vitamin D supplementation on glycaemic control and insulin resistance: a systematic review and meta-analysis. Diabet Med 2012; 29(8): e142-e150.

http://dx.doi.org/10.1111/j.1464-5491.2012.03672.x

[65] Belenchia AM, Tosh AK, Hillman LS, Peterson CA. Correcting vitamin $D$ insufficiency improves insulin sensitivity in obese adolescents: a randomized controlled trial. Am J Clin Nutr 2013; 97(4): 774-81.

http://dx.doi.org/10.3945/ajcn.112.050013

[66] Mathieu C, Gysemans C, Giulietti A, Bouillon R. Vitamin D and diabetes. Diabetologia 2005; 48(7): 1247-57. http://dx.doi.org/10.1007/s00125-005-1802-7

[67] Scragg R, Holdaway I, Singh V, Metcalf P, Baker J, Dryson E. Serum 25-hydroxyvitamin D3 levels decreased in impaired glucose tolerance and diabetes mellitus. Diabetes Res Clin Pract 1995; 27(3): 181-8.

http://dx.doi.org/10.1016/0168-8227(95)01040-K

[68] Scragg R, Sowers M, Bell C. Serum 25-hydroxyvitamin D, diabetes, and ethnicity in the Third National Health and Nutrition Examination Survey. Diabetes Care 2004; 27(12): 2813-8.

http://dx.doi.org/10.2337/diacare.27.12.2813

[69] Kabadi SM, Lee BK, Liu L. Joint effects of obesity and vitamin $D$ insufficiency on insulin resistance and type 2 diabetes: results from the NHANES 2001-2006. Diabetes Care 2012; 35(10): 2048-54.

http://dx.doi.org/10.2337/dc12-0235

[70] Mattila C, Knekt P, Mannisto S, et al. Serum 25hydroxyvitamin $\mathrm{D}$ concentration and subsequent risk of type 2 diabetes. Diabetes Care 2007; 30(10): 2569-70. http://dx.doi.org/10.2337/dc07-0292
[71] Kumar S, Davies M, Zakaria Y, et al. Improvement in glucose tolerance and beta-cell function in a patient with vitamin $D$ deficiency during treatment with vitamin D. Postgrad Med J 1994; 70(824): 440-3.

http://dx.doi.org/10.1136/pgmj.70.824.440

[72] Isaia G, Giorgino R, Adami S. High prevalence of hypovitaminosis $\mathrm{D}$ in female type 2 diabetic population. Diabetes Care 2001; 24(8): 1496. http://dx.doi.org/10.2337/diacare.24.8.1496

[73] Mathieu C, Waer M, Laureys J, Rutgeerts O, Bouillon R. Prevention of autoimmune diabetes in NOD mice by 1,25 dihydroxyvitamin D3. Diabetologia 1994; 37(6): 552-8. http://dx.doi.org/10.1007/BF00403372

[74] Sooy K, Schermerhorn T, Noda M, et al. Calbindin-D(28k) controls $[\mathrm{Ca}(2+)](\mathrm{i})$ and insulin release. Evidence obtained from calbindin-d(28k) knockout mice and beta cell lines. J Biol Chem 1999; 274(48): 34343-9. http://dx.doi.org/10.1074/jbc.274.48.34343

[75] Sandler S, Buschard K, Bendtzen K. Effects of 1,25dihydroxyvitamin D3 and the analogues MC903 and KH1060 on interleukin-1 beta-induced inhibition of rat pancreatic islet beta-cell function in vitro. Immunol Lett 1994; 41(1): 73-7. http://dx.doi.org/10.1016/0165-2478(94)90059-0

[76] Vaidya A, Williams JS, Forman JP. The independent association between 25-hydroxyvitamin $\mathrm{D}$ and adiponectin and its relation with BMI in two large cohorts: the NHS and the HPFS. Obesity (Silver Spring) 2012; 20(1): 186-91. http://dx.doi.org/10.1038/oby.2011.210

[77] Wolfson N, Gavish D, Matas Z, Boaz M, Shargorodsky M. Relation of adiponectin to glucose tolerance status, adiposity, and cardiovascular risk factor load. Exp Diabetes Res 2012; 2012: $1-5$.

http://dx.doi.org/10.1155/2012/250621

[78] Zittermann A. Vitamin D in preventive medicine: are we ignoring the evidence? Br J Nutr 2003; 89(5): 552-72. http://dx.doi.org/10.1079/BJN2003837

[79] Vieth R. Vitamin D supplementation, 25-hydroxyvitamin D concentrations, and safety. Am J Clin Nutr 1999; 69(5): 84256 .

[80] Taylor $\mathrm{WH}$, Khaleeli AA. Coincident diabetes mellitus and primary hyperparathyroidism. Diabetes Metab Res Rev 2011; 17(3): 175-80. http://dx.doi.org/10.1002/dmrr.199

[81] Beilfuss J, Berg V, Sneve M, Jorde R, Kamycheva E. Effects of a 1-year supplementation with cholecalciferol on interleukin-6, tumor necrosis factor-alpha and insulin resistance in overweight and obese subjects. Cytokine 2012; 60(3): 870-4. http://dx.doi.org/10.1016/j.cyto.2012.07.032

[82] Peterson CA, Heffernan ME. Serum tumor necrosis factoralpha concentrations are negatively correlated with serum $25(\mathrm{OH}) \mathrm{D}$ concentrations in healthy women. J Inflamm (Lond) 2008; 5 : 10

http://dx.doi.org/10.1186/1476-9255-5-10

[83] Shab-Bidar S, Neyestani TR, Djazayery A, Eshraghian MR, Houshiarrad A, Kalayi A, et al. Improvement of vitamin D status resulted in amelioration of biomarkers of systemic inflammation in the subjects with type 2 diabetes. Diabetes Metab Res Rev 2012; 28(5): 424-30. http://dx.doi.org/10.1002/dmrr.2290

[84] Shedeed SA. Vitamin D supplementation in infants with chronic congestive heart failure. Pediatr Cardiol 2012; 33(5): 713-9.

http://dx.doi.org/10.1007/s00246-012-0199-6

[85] Bucharles S, Barberato $\mathrm{SH}$, Stinghen $\mathrm{AE}$, et al. Impact of cholecalciferol treatment on biomarkers of inflammation and myocardial structure in hemodialysis patients without hyperparathyroidism. J Ren Nutr 2012; 22(2): 284-91. http://dx.doi.org/10.1053/j.jpr.2011.07.001 
[86] Hopkins $\mathrm{MH}$, Owen $\mathrm{J}$, Ahearn $\mathrm{T}$, et al. Effects of supplemental vitamin $D$ and calcium on biomarkers of inflammation in colorectal adenoma patients: a randomized, controlled clinical trial. Cancer Prev Res (Phila) 2011; 4(10): 1645-54.

http://dx.doi.org/10.1158/1940-6207.CAPR-11-0105
[87] Sergeev I, Song Q. High vitamin D and calcium intakes reduce diet-induced obesity in mice by increasing adipose tissue apoptosis. Mol Nutr Food Res 2014; 58(6): 1342-8. http://dx.doi.org/10.1002/mnfr.201300503

[88] Soskic S, Stokic E, Isenovic E. The relationship between vitamin D and obesity. CMRO 2014; 30(6): 1197-9. http://dx.doi.org/10.1185/03007995.2014.900004 